\title{
BMJ Open Preparing social workers to address health inequities emerging during the COVID-19 pandemic by building capacity for health policy: a scoping review protocol
}

Rachelle Ashcroft (D) , ${ }^{1}$ Simon Lam, ${ }^{1}$ Toula Kourgiantakis (D) , ${ }^{1}$ Stephanie Begun, ${ }^{1}$ Michelle L A Nelson, ${ }^{2,3}$ Keith Adamson, ${ }^{1}$ Susan Cadell, ${ }^{4}$ Benjamin Walsh, ${ }^{5}$ Andrea Greenblatt, ${ }^{1}$ Amina Hussain (1) , ${ }^{1}$ Deepy Sur, ${ }^{6}$ Frank Sirotich, ${ }^{7}$ Shelley L Craig ${ }^{1}$

To cite: Ashcroft R, Lam S, Kourgiantakis T, et al. Preparing social workers to address health inequities emerging during the COVID-19 pandemic by building capacity for health policy: a scoping review protocol. BMJ Open 2021;11:e053959. doi:10.1136/ bmjopen-2021-053959

- Prepublication history and additional supplemental material for this paper are available online. To view these files, please visit the journal online (http://dx.doi.org/10.1136/ bmjopen-2021-053959).

Received 29 May 2021 Accepted 13 October 2021

Check for updates

(c) Author(s) (or their employer(s)) 2021. Re-use permitted under CC BY-NC. No commercial re-use. See rights and permissions. Published by BMJ.

For numbered affiliations see end of article.

Correspondence to Dr Rachelle Ashcroft; rachelle.ashcroft@utoronto.ca

\section{ABSTRACT}

Introduction The COVID-19 pandemic has brought tremendous changes in healthcare delivery and exacerbated a wide range of inequities. Social workers across a broad range of healthcare settings bring an expertise in social, behavioural and mental healthcare needed to help address these health inequities. In addition, social workers integrate policy-directed interventions and solutions in clinical practice, which is a needed perspective for recovery from the COVID-19 pandemic. It remains unclear, however, what the most pressing policy issues are that have emerged during the COVID-19 pandemic. In addition, many social workers in health settings tend to underuse policy in their direct practice. The objectives of this scoping review are to: (1) systematically scope the literature on social work, COVID-19 pandemic and policy; and (2) describe the competencies required by social workers and the social work profession to address the policy issues emerging during the COVID-19 pandemic.

Methods and analysis The scoping review follows Arksey and 0'Malley's five-stage framework. Identification of literature published between 1 December 2019 and the search date, 31 March 2021, will take place in two stages: (1) title and abstract review, and (2) full-text review. In partnership with a health science librarian, the research team listed keywords related to social work and policy to search databases including Medline, Embase, PsycINF0, CINAHL, Social Services Abstract and Social Work Abstracts. Two graduate-level research assistants will conduct screening and full-text review. Data will then be extracted, charted, analysed and summarised to report on our results and implications on practice, policy and future research.

Ethics and dissemination Results will help develop a policy practice competence framework to inform how social workers can influence policy. We will share our findings through peer-reviewed publications and conference presentations. This study does not require Research Ethics Board approval as it uses publicly available sources of data.

\section{Strengths and limitations of this study}

- This will be the first scoping review study to identify policy issues that emerged during the COVID-19 pandemic.

- Scoping reviews cover a vast volume of literature and will provide guidance to social workers in healthcare to help advance recovery from the COVID-19 pandemic.

- Inclusion criteria are limited to English.

- No formal assessment of quality will be applied to articles included in this study.

\section{INTRODUCTION}

The COVID-19 pandemic has had devastating social and economic impacts worldwide. ${ }^{1}$ People have experienced major unexpected financial pressure, job loss, food insecurity, precarious housing and living conditions, discrimination, grief, isolation and reduced access to health and social services. ${ }^{2-5}$ Disparities within communities have widened during the pandemic with a disproportionate impact on older adults, children and youth, people with reduced access to socioeconomic resources and those with disabilities. ${ }^{346-8}$ It is well documented that those who are socially and economically vulnerable disproportionally suffer the greatest burden of disease-including comorbidities, mortality, socioeconomic costs and decreased access to resources-as is evident with the COVID-19 pandemic. ${ }^{9-12}$ Clinical health professionalslike physicians, nurses and social workerscan often feel helpless when faced with these complex social and economic challenges perpetuating health disparities in the lives of their patients. ${ }^{13}$ Building health professionals' 
capacity to understand, apply, critique and/or shape policies that contribute to such disparities is increasingly recognised as a strategy to improve population health. ${ }^{13}$

\section{Health inequities and COVID-19}

The COVID-19 pandemic has exposed the magnitude of existing health inequities in Canada, the USA and worldwide. ${ }^{2414}$ Health inequity refers to the "unfair, avoidable, and remedial differences' in health outcomes ${ }^{15}$ which are inextricably linked to policy. ${ }^{16}$ For example, 'data support the important role that residential segregation of black and white people, because of racist housing policies, has played in health disparities by race in the United States, leading to higher rates of child poverty and adverse birth outcomes among black children than among white children'. ${ }^{16}$ Historically, pandemics expose and exacerbate health inequities. ${ }^{17}$ This is evident with the COVID-19 pandemic, which has heightened existing inequities for racialised populations, children, older adults and those with greater financial precarity. ${ }^{3} 478$ There is a long-standing recognition of the connection between social determinants and health. ${ }^{18}{ }^{19}$ Social determinants of health are social, behavioural and economic factors that shape the health of individuals and communities. ${ }^{19}$ These social-structural conditions can also act as an access barrier to preventative and comprehensive healthcare services. ${ }^{20}$ Recent research has shown that poverty, homelessness, racism and social exclusion can have a significant impact on COVID-19 outcomes, yet the effect of these social-structural determinants is thought to be greatly underestimated. ${ }^{221}$

The rates of COVID-19 have highlighted disparities among racialised communities, ${ }^{46}$ with mortality rates that are 'more than twice as high in Black, Latinx, and Indigenous populations as in White populations, and the data reveal a strong socioeconomic gradient'. ${ }^{14}$ Children and youth are also at increased risk of indirect harms emerging from the pandemic, including adverse childhood experiences such as maltreatment, mental health problems and poverty. ${ }^{22}$ For older adults, there are elevated risks of social isolation, neglect and death due to COVID-19. ${ }^{8}$ Furthermore, populations with low income have been found to have disproportionately elevated rates of infection, hospitalisations and deaths related to COVID-19, and neighbourhoods with the greatest material deprivation and lowest income have been found to have higher rates of confirmed positive COVID-19 tests. ${ }^{23}{ }^{24}$ In addition, lowincome and precariously employed workers have higher exposure risk at work related to physical proximity to others, yet have less access to paid sick leave. ${ }^{25}$ Recovery from the COVID-19 pandemic requires mobilisation of strategies and interventions that address the range of social, behavioural and socioeconomic health crises instigated and exacerbated during the pandemic. ${ }^{26} 27$

\section{The role of policy in the recovery from COVID-19}

Recovery from the COVID-19 pandemic requires greater attention to policies that reduce inequities. ${ }^{28}$ Policy refers to a set of inter-related decisions taken by a group of actors that identify particular goals and the means of achieving them within a specified situation. ${ }^{29}$ Health policy provides 'a course of action or inaction chosen by public authorities to address an issue that deals with human health'. Public policies are those established by governments whereas institutional policies are developed by organisations for institutional use. ${ }^{16}$ Public policies tend to be legally binding, which means that individuals and/or institutions must comply with them. ${ }^{16}$ However, policies developed by organisations do not carry the force of law yet compliance within the specified institutions may be required. ${ }^{16}$ Policy establishes a future vision, establishes priorities, outlines expected roles of different groups, builds consensus and shapes healthcare delivery across all sectors and all levels. ${ }^{29} 31$ They can also reduce inequities through distribution of various resources, enabling access to services, and facilitating the delivery of a broad range of health and social services. ${ }^{28} 29$

New policies were implemented during the pandemic to contain the spread of the coronavirus, mitigate the impact of recurrent waves of infection, sustain life in pandemic conditions and allocate immediate resources. ${ }^{28}$ There are some early examples of policy responses implemented to mitigate the pandemic's overwhelming social and public health crisis. ${ }^{632}$ For example, these include physical distancing, school and business closures, reduction of in-person health and social services, lockdowns, quarantine and mandatory use of face masks. Another example of policy's role in mitigating the economic impact of the COVID-19 pandemic is demonstrated by the various national, provincial and state-level safety net programmes-like the Canada Emergency Response Benefit (CERB) - providing financial support to individuals during the pandemic. ${ }^{33}{ }^{34}$ However, it is unclear how policy is being applied in clinical settings to guide patientrelated interventions by different healthcare providers. As we move beyond the immediate threats into a phase of recovery, the conditions for an equitable recovery require greater attention on the implementation of policies that help address the range of inequitable conditions and outcomes of the pandemic. ${ }^{28}$

\section{Addressing health inequities: the role of social work}

Social workers are clinical practice-based health professionals informed by the value of social justice with a commitment to address existing health inequities and alleviate future disparities. ${ }^{356}$ Social workers are uniquely positioned across the healthcare system-in hospitals, primary healthcare, public health, community settings, non-profit organisations and elsewhere-to respond to the complex social and psychological impacts emerging from the pandemic. ${ }^{37}$ Social work has a foundational systems perspective that uses interventions spanning across the microlevels, mesolevels and macrolevels. ${ }^{38}$ Microlevels, mesolevels and macrolevels are foundations of social theory that help categorise social structures and processes of the determinants of health contributing to 
health inequities, and the responses designed to address health inequities. ${ }^{39} 40$ The microlevel includes individual psychosocial, behavioural and material risk factors while the mesolevel refers to organisational and institutional structures. The macrolevel encompasses societal-level characteristics such as healthcare policy, societal norms and income distribution. ${ }^{39}$

Social work harnesses a range of skills and competencies of importance to the emerging needs of the pandemic including risk assessments; crisis management; advanced care planning; individual, family and group therapy; case management; advocacy; systems navigation; problem solving; resource allocation; and community mobilisation. ${ }^{41-43}$ Social workers are integral in assisting with the range of psychosocial and mental health needs emerging during the pandemic, ${ }^{4744}$ including helping patients navigate accessing of relevant financial resources like CERB. Across a broad range of practice settings, social workers have been visible in fighting for social justice, particularly against the drastic increases of racism and xenophobia during the COVID-19 pandemic. ${ }^{45}$ Emerging scholarship demonstrates the essential role of social work in responding to the pandemic's social crisis. ${ }^{46}$ There has even been an increased demand for social work's involvement in policy-level decisions during the COVID-19 pandemic to help address some of the inequitable structural systems and social determinants of health issues emerging during this public health crisis. ${ }^{1}{ }^{646}$

\section{Social work and policy}

'Policy practice' is a unique practice framework that guides social workers' integration of policy in their professional roles. ${ }^{47}$ The purpose of the policy practice framework is to enable social workers in all settings to systematically and concurrently address patients' immediate clinical issues, while addressing policies that shape the provision of services and resources surrounding the patients' needs. ${ }^{47}{ }^{48}$ Employing a policy practice framework means acting as a policy expert, enacting and implementing policy, mediating existing policy, providing input to organisational leaders and policymakers and/ or creating policy itself. ${ }^{47-49}$ As Jansson describes, policy practice takes a broad view of policy and includes 'efforts to change policies in legislative, agency, and community settings, whether by establishing new policies [or] improving existing ones, ${ }^{50}$ By implementing a policy practice approach, social workers can be allies to interdisciplinary health teams in efforts to eliminate inequities and improve population health. ${ }^{51}$ Despite the benefits of adopting a policy practice approach, most social workers do not engage in policy practice. ${ }^{52}$ Building capacity for social workers in healthcare to engage in policy practice will help address rising health inequities that are emerging during the COVID-19 pandemic.

\section{Rationale}

Social workers can help address the vast inequities that have emerged during the COVID-19 pandemic by integrating a policy practice framework in their professional roles across various health and social settings. The COVID-19 pandemic has brought tremendous changes in healthcare delivery; complex social, behavioural and socioeconomic health crises; and a wide range of inequities. ${ }^{146}$ It remains unclear, however, what the most pressing policy issues are that have emerged during the COVID-19 pandemic. In addition, many social workers in health settings tend to overlook the role of policy and/or underused policy in their direct practice, in part because they are unclear how to integrate policy in their practice. ${ }^{30}{ }^{49}$ Furthermore, enhancing social workers' knowledge about policies underpinning social safety net programmes integral for patients during the COVID-19 pandemic would better enable them to advocate for social and economic justice in multiple settings and on numerous levels. ${ }^{53}$ The objectives of this scoping review are to: (1) systematically scope the literature on social work, COVID-19 pandemic and policy; and (2) describe the competencies required by social workers and the social work profession to address the policy issues emerging during the COVID-19 pandemic. This information will help provide guidance to social workers and social work leaders and educators by informing how to prepare social workers for their role in the recovery from the pandemic.

\section{METHODS AND ANALYSIS}

Our study uses scoping review methods to provide a broader understanding of the competencies required by social workers to address the policy issues emerging during the COVID-19 pandemic. A scoping review is a method of knowledge synthesis appropriate for an exploratory research question intended to map key concepts, research evidence and research gaps in a particular field. ${ }^{54}$ Scoping reviews systematically search, review and synthesise existing knowledge and are particularly useful when there is minimal literature on a particular topic. ${ }^{54-56}$ Knowledge synthesis such as scoping reviews is useful for identifying key concepts and evidence that can help guide practice and policy, and advance healthcare practices by guiding efficient evidence-based decisions in practice. ${ }^{54}$ We followed the Preferred Reporting Items for Systematic Reviews and Meta-Analyses Extension for Scoping Review (PRISMA-ScR) checklist in the reporting of the methodology of this scoping review (see online supplemental file 1). There are no competing interests.

The methods for our scoping review are based on a fivestage framework proposed by Arksey and O'Malley. ${ }^{55}$ The five stages of the scoping review are: (1) identifying the research question; (2) identifying the relevant studies; (3) study selection; (4) charting the data; and (5) data summary and synthesis of results. ${ }^{55}$ This review will adhere to the PRISMA-ScR guidelines. ${ }^{57}$

\section{Stage 1: identifying the research question}

The research questions emerged while conducting research on the impact of the COVID-19 pandemic on 
social work practice. ${ }^{58}{ }^{59}$ Levac et $a l^{60}$ recommend developing a broad research question that defines the target population, concept and intended outcomes. The following research questions were developed by the principal investigator (RA) in collaboration with the research team:

1. What are the policy issues that have emerged during the COVID-19 pandemic that are important for social workers?

2. What are the competencies required by social workers to address the policy issues emerging during the COVID-19 pandemic?

\section{Stage 2: identifying relevant studies}

At stage 2, we seek to identify the available literature on policy issues relevant to social work during the COVID-19 pandemic. We have assembled a team comprising experts and leaders in social work practice in health and mental health, health policy, leadership and scoping review methodology. We have identified two graduate-level research assistants who will participate in all phases of the scoping review. In addition, the research team includes a librarian at the University of Toronto, Canada, to determine the appropriate databases and keywords for our scoping review. Databases will be searched using textwords and, wherever possible, subject headings and validated searches. Database search fields to be examined for textwords will include title, abstract and authorassigned keyword (wherever possible). A pilot search of Medline will be translated for use in all other databases to ensure consistency across search platforms and in results. In addition to Medline, we will also search in Embase, PsycINFO, CINAHL, Social Services Abstracts and Social Work Abstracts. Search terms development was led by the health sciences librarian with input provided by the research team.

Concepts guiding database searches are from two broad themes: social work and COVID-19 pandemic. A third concept, policy, will be introduced during the screening process. This decision addresses the difficulty of generating exhaustive policy-related textwords due to the varied application of 'policy' in social work and social work adjacent practices.

Table 1 provides the terms used during full-text screening to identify the articles with a policy focus.

In addition to searching the noted databases, we will conduct a search of the grey literature to identify any non-indexed literature of relevance to the scoping review. The grey literature search will focus on Canadian and US government reports, professional organisation publications and reports, as well as relevant pandemic response guidelines. Finally, we will contact other national experts in the field of social work policy and consulted through a 'desk drawer search' in order to ensure that all relevant data are obtained.

A date limitation will be applied to limit results to those reflective of the COVID-19 pandemic. All results will have been published between 1 December 2019
Table 1 Terms used during screening to identify articles with a policy focus

\begin{tabular}{|c|c|c|}
\hline \multicolumn{3}{|c|}{ List of terms } \\
\hline Antioppression & Human rights & Racism \\
\hline Antiracism & Inequality & Reform \\
\hline Community & Inequity & Society \\
\hline Delivery of care & Law & Social assistance \\
\hline Discrimination & Leadership & $\begin{array}{l}\text { Social } \\
\text { determinants of } \\
\text { health }\end{array}$ \\
\hline Equity & Legal & Social justice \\
\hline Economic & Legislation & Social safety net \\
\hline $\begin{array}{l}\text { Environmental social } \\
\text { work }\end{array}$ & Macro & Social movement \\
\hline Federal & Meso & $\begin{array}{l}\text { Socioeconomic } \\
\text { status }\end{array}$ \\
\hline Food insecurity & Multisectoral & $\begin{array}{l}\text { Structural/ } \\
\text { structure }\end{array}$ \\
\hline Funding & Municipal & Transformation \\
\hline Government & National & $\begin{array}{l}\text { Truth and } \\
\text { reconciliation }\end{array}$ \\
\hline Guidelines & $\begin{array}{l}\text { Organisation of } \\
\text { care }\end{array}$ & Union/unionised \\
\hline $\begin{array}{l}\text { Health services } \\
\text { (health } \\
\text { system/healthcare } \\
\text { delivery/social } \\
\text { care/social services) }\end{array}$ & Organisational & Welfare state \\
\hline \multirow[t]{5}{*}{ Housing } & Policy & $\begin{array}{l}\text { Any specific } \\
\text { policy (eg, Medical } \\
\text { Assistance in } \\
\text { Dying) }\end{array}$ \\
\hline & $\begin{array}{l}\text { Population } \\
\text { health }\end{array}$ & \\
\hline & Public health & \\
\hline & Poverty & \\
\hline & Provincial & \\
\hline
\end{tabular}

and the search date, 31 March 2021. Search results will be downloaded and imported into the online platform Covidence. The online supplemental file 2 displays the search terms used to identify relevant studies for this scoping review.

\section{Stage 3: study selection}

The stage 3 study selection process includes two levels of screening: a title and abstract review, and a full-text review. For the first level of screening, we have identified two graduate-level research assistants-working under supervision of the principal investigator-who will independently conduct a review of the title and abstract for each article to determine eligibility based on our inclusion criteria (outlined below). The two research assistants will both screen the same first 100 abstracts in order 
to calibrate their study selection. We will be aiming for a similarity of $75 \%$ or higher between the two research assistants. ${ }^{61}$ Once this is achieved, the remaining articles will be reviewed independently by the two research assistants. Articles that are deemed relevant will be included for the full-text review. Both research assistants will then screen each article selected for a full-text review. The lead investigator will resolve conflicts arising between the two research assistants (ie, if an article is screened by one research assistant but rejected by another) with regard to inclusion/exclusion of articles.

Inclusion criteria for publications are all types of literature including peer-reviewed publications and grey literature, English language and published on or after 1 December 2019. Relevant articles will be assessed against the following inclusion criteria: (1) the words social work (inclusive of search terms) and COVID-19 pandemic (inclusive of search terms) are used in the title or abstract; (2) there is a focus on policy-related issues identified in the title or abstract; and (3) social work is a key focus of the article.

Any type of peer-reviewed article is eligible for inclusion comprising all types of study designs. Relevant articles can include literature or systematic reviews, conceptual or theoretical papers, and empirical research. Following Levac et $a l \mathrm{~s}^{60}$ recommendation, we will consider stage 3 an iterative process and will hold regular team meetings to discuss study inclusion/exclusion at various stages in the process.

\section{Stage 4: charting the data}

We will extract data from all articles included in the scoping review and chart this in a spreadsheet in Microsoft Excel. Identified themes will be charted to present the content as it relates to the scoping review research questions. Sample charting categories include, but are not limited to: authors, publication year, type of article, study design, geographical location, description of social work practice setting, type of policy issue(s), level of policy (eg, national, provincial/state, institutional), type of social work practice activities and characteristics of practice activities. One graduate-level research assistant will conduct the data extraction, working under the supervision of the principal investigator. Following Levac et $a l \mathrm{~s}^{60}$ recommendation, the research team will review the spreadsheet and identify any emerging connections or themes pertaining to social work practice, the COVID-19 pandemic and policy work. Data used in this study are available in public domain as this is a scoping review using publicly available content.

\section{Stage 5: data summary and synthesis of results}

At stage 5, we will provide a summary and synthesis of the results. The purpose of scoping reviews is to provide an overview of concepts that are foundational to the research. We will report our results and will include the charted findings as tables in our synthesis. Following Levac et al's suggestion, we will consider the implications of our findings on practice, policy and future research. To achieve our study objectives, we will share the findings at conferences and in journals that specifically target social workers in healthcare and social work educators.

\section{Patient and public involvement}

There is no patient involvement in this study.

\section{ETHICS AND DISSEMINATION}

This study will be a first step to developing a policy practice competency framework for social workers involved in the recovery of the pandemic. Research ethics approval is not necessary given that we are using publicly available sources to collect data. Results of this scoping review study will be disseminated through a peer-reviewed publication as well as through a conference presentation that engages an audience of social work practitioners and leaders. All members of the research team have established relationships with social workers, which we will also use to disseminate findings. Our aim is to use findings from this scoping review to guide future social work practice by providing a more in-depth understanding of policy issues emerging during the COVID-19 pandemic. Social workers employed in health settings are often working in collaboration with other healthcare professionals as members of interdisciplinary teams. ${ }^{62-64}$ Thus, findings from our scoping review will also benefit the broad range of healthcare professionals with whom social workers work with as allies. ${ }^{64}$

\section{Author affiliations}

${ }^{1}$ Factor-Inwentash Faculty of Social Work, University of Toronto, Toronto, Ontario, Canada

${ }^{2}$ Bridgepoint Collaboratory for Research and Innovation, Lunenfeld-Tanenbaum Research Institute, Sinai Health System, Toronto, Ontario, Canada

${ }^{3}$ Institute of Health Policy, Management and Evaluation, University of Toronto,

Toronto, Ontario, Canada

${ }^{4}$ Renison University College, Waterloo, Ontario, Canada

${ }^{5}$ Robarts Library, University of Toronto, Toronto, Ontario, Canada

${ }^{6}$ Ontario Association of Social Workers, Toronto, Ontario, Canada

${ }^{7}$ Canadian Mental Health Association, Toronto, Ontario, Canada

\section{Twitter Toula Kourgiantakis @DrKourgiantakis}

Contributors All authors conceptualised and designed the study. RA, SL and BW created the scoping review search framework. RA and SL wrote the initial study protocol, which was then revised by TK, SB, MLAN, KA, SC, BW, AG, AH, DS, FS and SLC. RA and SL took the lead and compiled the revisions. All authors approved the final protocol manuscript and agreed to be accountable to all aspects of the work.

Funding This work was supported by the Factor-Inwentash Faculty of Social Work's Dean's Network Award at the University of Toronto.

Competing interests None declared.

Patient consent for publication Not applicable.

Provenance and peer review Not commissioned; externally peer reviewed.

Supplemental material This content has been supplied by the author(s). It has not been vetted by BMJ Publishing Group Limited (BMJ) and may not have been peer-reviewed. Any opinions or recommendations discussed are solely those of the author(s) and are not endorsed by BMJ. BMJ disclaims all liability and responsibility arising from any reliance placed on the content. Where the content includes any translated material, BMJ does not warrant the accuracy and reliability 
of the translations (including but not limited to local regulations, clinical guidelines, terminology, drug names and drug dosages), and is not responsible for any error and/or omissions arising from translation and adaptation or otherwise.

Open access This is an open access article distributed in accordance with the Creative Commons Attribution Non Commercial (CC BY-NC 4.0) license, which permits others to distribute, remix, adapt, build upon this work non-commercially, and license their derivative works on different terms, provided the original work is properly cited, appropriate credit is given, any changes made indicated, and the use is non-commercial. See: http://creativecommons.org/licenses/by-nc/4.0/.

\section{ORCID iDs}

Rachelle Ashcroft http://orcid.org/0000-0002-5666-1946

Toula Kourgiantakis http://orcid.org/0000-0002-2491-2595

Amina Hussain http://orcid.org/0000-0002-8697-0360

\section{REFERENCES}

1 Banks S, Cai T, de Jonge E, et al. Practising ethically during COVID-19: social work challenges and responses. Int Soc Work 2020;63:569-83.

2 Abrams EM, Szefler SJ. COVID-19 and the impact of social determinants of health. Lancet Respir Med 2020;8:659-61.

3 Berg-Weger M, Morley JE. Editorial: Ioneliness and social isolation in older adults during the COVID-19 pandemic: implications for Gerontological social work. J Nutr Health Aging 2020;24:456-8.

4 Walter-McCabe HA. Coronavirus pandemic calls for an immediate social work response. Soc Work Public Health 2020;35:69-72.

5 Dennis MK. Collecting grief: Indigenous peoples, deaths by police and a global pandemic. Qual Soc Work 2021;20:149-55.

6 Walter-McCabe HA. Coronavirus health inequities in the United States highlight need for continued community development Efforts* The International Journal of Community and Social Development 2020;2:211-33.

7 Amadasun S, work S. Social work and COVID-19 pandemic: an action call. Int Soc Work 2020;63:753-6.

8 Armitage R, Nellums LB. COVID-19 and the consequences of isolating the elderly. Lancet Public Health 2020;5:e256.

9 Rangel JC, Ranade S, Sutcliffe P, et al. COVID-19 policy measures Advocating for the inclusion of the social determinants of health in modelling and decision making. J Eval Clin Pract 2020;26:1078-80.

10 Braveman P, Egerter S, Williams DR. The social determinants of health: coming of age. Annu Rev Public Health 2011;32:381-98.

11 Mikkonen J, Raphael D. The Canadian facts. Toronto, ON: York University School of Health Policy and Management, 2010.

12 Adler NE, Stewart J. Preface to the biology of disadvantage: socioeconomic status and health. Ann N Y Acad Sci 2010;1186:1-4

13 Andermann A, CLEAR Collaboration. Taking action on the social determinants of health in clinical practice: a framework for health professionals. CMAJ 2016;188:E474-83.

14 Berkowitz SA, Cené CW, Chatterjee A. Covid-19 and Health Equity Time to Think Big. N Engl J Med 2020;383:e76.

15 World Health Organization. Closing the health equity gap: policy options and opportunities for action. Geneva, Switzerland: World Health Organization, 2013.

16 Pollack Porter KM, Rutkow L, McGinty EE. The importance of policy change for addressing public health problems. Public Health Rep 2018;133:9S-14.

17 Kawachi I. COVID-19 and the 'rediscovery' of health inequities. Int J Epidemiol 2020;49:1415-8.

18 Ashcroft R. Health promotion and primary health care: examining the discourse. Soc Work Public Health 2015;30:107-16.

19 Raphael D. Chapter 6: Social determinants of health. In: Raphael D, Teeple G, eds. Staying alive: critical perspectives on health, illness, and health care. Toronto: Canadian Scholars' Press, 2019.

20 Haggerty J, Levesque J-F, Harris M, et al. Does healthcare inequity reflect variations in peoples' abilities to access healthcare? results from a multi-jurisdictional interventional study in two high-income countries. Int J Equity Health 2020;19:167.

21 Ruckert A, Shedeed E, Hillier S. The Canadian policy response to COVID-19: What's in it for health equity? 2021

22 Chanchlani N, Buchanan F, Gill PJ. Addressing the indirect effects of COVID-19 on the health of children and young people. CMAJ 2020;192:E921-7.

23 Thakur N, Lovinsky-Desir S, Bime C, et al. The structural and social determinants of the racial/ethnic disparities in the U.S. COVID-19 pandemic. what's our role? Am J Respir Crit Care Med 2020;202:943-9.
24 Chen JT, Krieger N. Revealing the unequal burden of COVID-19 by income, race/ethnicity, and household crowding: US County versus ZIP code analyses. J Public Health Manag Pract 2021;27:S43-56.

25 Public Health Ontario. COVID-19 - what we know so far About... social determinants of health, 2020. Available: https://www. publichealthontario.ca/-/media/documents/ncov/covid-wwksf/2020/ 05/what-we-know-social-determinants-health.pdf?la=en

26 Hoernke K. A socially just recovery from the COVID-19 pandemic: a call for action on the social determinants of urban health inequalities. $J$ R Soc Med 2020;113:482-4

27 Paremoer L, Nandi S, Serag H, et al. Covid-19 pandemic and the social determinants of health. BMJ 2021;372:n129.

28 Lynch J. Health equity, social policy, and promoting recovery from COVID-19. J Health Polit Policy Law 2020;45:983-95.

29 Deber RB, Mah CL, eds. Case studies in Canadian health policy and management. Second ed. Toronto: University of Toronto Press, 2014.

30 Westhues A, ed. Canadian social policy: issues and perspectives. 4th ed. Waterloo, ON: Wilfrid Laurier Univ. Press, 2006.

31 Collins T. Health policy analysis: a simple tool for policy makers. Public Health 2005;119:192-6.

32 Lu Q, Cai Z, Chen B, et al. Social policy responses to the Covid-19 crisis in China in 2020. Int J Environ Res Public Health 2020;17:5896.

33 Petit G, Tedds LM. The effect of differences in treatment of the Canada emergency response benefit across provincial and territorial income assistance programs. Canadian Public Policy 2020;46:S29-43.

34 Saloner B, Gollust SE, Planalp C, et al. Access and enrollment in safety net programs in the wake of COVID-19: a national crosssectional survey. PLoS One 2020;15:e0240080.

35 Ashcroft R. Health inequities: evaluation of two paradigms. Health Soc Work 2010;35:249-56.

36 Walters KL, Spencer MS, Smukler M. Health equity: eradicating health inequalities for future generations. Cleveland, $\mathrm{OH}$ : American Academy of Social Work and Social Welfare, 2016.

37 Ross AM, Schneider S, Muneton-Castano YF, et al. "You never stop being a social worker:" Experiences of pediatric hospital social workers during the acute phase of the COVID-19 pandemic. Soc Work Health Care 2021;60:8-29.

38 Payne M. Modern social work theory. London, UK: Red Globe Press, 2021.

39 Richter M, Dragano N, Micro DN. Micro, macro, but what about meso? the institutional context of health inequalities. Int $J$ Public Health 2018;63:163-4.

40 Serpa S, Miguel Ferreira C. Sociological problem and social problem: contributions to a discussion. Sociol Anthropol 2018;6:840-4.

41 Bern-Klug M, Beaulieu E. COVID-19 highlights the need for trained social workers in nursing homes. J Am Med Dir Assoc 2020;21:970-2.

42 Ashcroft R, McMillan C, Ambrose-Miller W, et al. The emerging role of social work in primary health care: a survey of social workers in Ontario family health teams. Health Soc Work 2018;43:9.

43 Steketee G, Ross AM, Wachman MK. Health outcomes and costs of social work services: a systematic review. Am J Public Health 2017; 107:S256-66.

44 Holmes EA, O'Connor RC, Perry VH, et al. Multidisciplinary research priorities for the COVID-19 pandemic: a call for action for mental health science. Lancet Psychiatry 2020;7:547-60.

45 Miller VJ, Lee H. Social work values in action during COVID-19. J Gerontol Soc Work 2020;63:565-9.

46 Truell R. News from our societies - IFSW: COVID-19: The struggle, success and expansion of social work - Reflections on the profession's global response, 5 months on. Int Soc Work 2020;63:545-8

47 Weiss-Gal I, Gal J. Explaining the policy practice of community social workers. Journal of Social Work 2020;20:216-33.

48 Watt S, Sword W, Krueger P. Implementation of a health care policy: an analysis of barriers and facilitators to practice change. BMC Health Serv Res 2005;5:53.

49 Powell TJ, Garrow E, Woodford MR, et al. Policymaking opportunities for direct practice social workers in mental health and addiction services. Adv Soc Work 2013;14:367-78.

50 Jansson BS. Becoming an effective policy advocate: from policy practice to social justice. 7th ed. Belmont, CA: Brooks/Cole, 2014.

51 Miller DP, Bazzi AR, Allen HL, et al. A social work approach to policy: implications for population health. Am J Public Health 2017;107:S243-9.

52 Pawar M. Social work and social policy practice: imperatives for political engagement. The International Journal of Community and Social Development 2019;1:15-27. 
53 Gillen M, Loeffler DN. Financial literacy and social work students: knowledge is power. J Financ Ther 2012;3.

54 Colquhoun HL, Levac D, O'Brien KK, et al. Scoping reviews: time for clarity in definition, methods, and reporting. J Clin Epidemiol 2014;67:1291-4.

55 Arksey H, O'Malley L. Scoping studies: towards a methodological framework. Int J Soc Res Methodol 2005;8:19-32.

56 Daudt HML, van Mossel C, Scott SJ. Enhancing the scoping study methodology: a large, inter-professional team's experience with Arksey and O'Malley's framework. BMC Med Res Methodol 2013;13:48.

57 Tricco AC, Lillie E, Zarin W, et al. PRISMA extension for scoping reviews (PRISMA-SCR): checklist and explanation. Ann Intern Med 2018;169:467-73.

58 Donnelly C, Ashcroft R, Bobbette $\mathrm{N}$, et al. Interprofessional primary care during COVID-19: a survey of the provider perspective. BMC Fam Pract 2021;22:31.
59 Ashcroft R, Menear M, Greenblatt A, et al. Patient perspectives on quality of care for depression and anxiety in primary health care teams: a qualitative study. Health Expect 2021;24:hex.13242

60 Levac D, Colquhoun H, O'Brien KK. Scoping studies: advancing the methodology. Implement Sci 2010;5:69.

$61 \mathrm{JBI}$. JBI manual for evidence synthesis. 11.2.6 source of evidence selection, 2020. Available: https://wiki.jbi.global/display/MANUAL/11. 2.6+Source+of+evidence+selection

62 Ambrose-Miller W, Ashcroft R. Challenges faced by social workers as members of interprofessional collaborative health care teams. Health Soc Work 2016;41:101-9.

63 Ashcroft R, Kourgiantakis T, Fearing G, et al. Social work's scope of practice in primary mental health care: A scoping review. The British Journal of Social Work 2019;49:318-34.

64 Craig SL, Eaton AD, Belitzky M, et al. Empowering the team: a social work model of interprofessional collaboration in hospitals. J Interprof Educ Pract 2020;19:100327. 